DOI: 10.12737/article_59c219d3b9a939.86624552

УДК: 338.43

РАЗВИТИЯ ЛЕСНОГО ХОЗЯЙСТВА МАЛОЛЕСНОГО РЕГИОНА: ОПЫТ И ПЕРСПЕКТИВЫ кандидат географических наук, заметитель руководителя Скрынникова М.В. ${ }^{1}$, аспирант, Топчеев А.Н. ${ }^{2}$

1 - Управление лесного хозяйства Воронежской области

2 - ФГБОУ ВО Воронежский государственный лесотехнический университет им. Г.Ф.Морозова

В статье рассмотрены основные направления развития лесного хозяйства в малолесном регионе. Изменения в лесном законодательстве привели к формированию в Воронежской области модели лесопользования ориентированной на развитие предпринимательства. Определено, что основной формой использования лесов в регионе является аренда лесных участков. Экономический механизм ведения лесного хозяйства в этих условиях должен опираться на баланс интересов участников лесных отношений (государства, общества, населения, бизнеса). На региональном уровне факторами ограничивающими развитие лесного хозяйства выступают большие затраты на проведение санитарно-оздоровительных мероприятий и сложности с утилизацией мелкотоварной и дровяной древесины от санитарных рубок и рубок ухода. Установлено, что трудности в предоставлении лесных участков в пользование связаны с имеющимся двойным учетом некоторых земельных и лесных участков в Едином госреестре недвижимости. За анализируемы период в регионе сложилась устойчивая тенденция в предпринимательской сфере лесного хозяйства к развитию государственно-частного партнерства. Доказано, что для реализации принципов устойчивого управления лесами и создания благоприятных условий для развития и внедрения экономически, экологически и социально ответственного освоения лесов необходима поддержка предпринимательской деятельности, в части создания региональных объектов инфраструктуры поддержки предпринимательства в сфере лесного хозяйства (отраслевых бизнес-инкубаторов на базе имеющихся НИИ в кооперации с ведущими лесными вузами) и обеспечение её деятельности.

Ключевые слова: лесное хозяйство, защита лесов, арендаторы лесных участков, лесной доход

\title{
FORESTRY DEVELOPMENT OF SPARSELY WOODED REGION: EXPERIENCE AND PERSPECTIVES
}

PhD (Geography), Deputy Head M. V. Skrynnikova ${ }^{1}$, Post-graduate student Topcheev A. N. ${ }^{2}$

1 - Department of Forestry of Voronezh region

2 - FSBEI HE «Voronezh State University of Forestry and Technologies named after G.F. Morozov» Voronezh, Russian Federation

\begin{abstract}
The article describes main directions of forestry development in sparsely wooded region. Changes in forest legislation have led to the formation of the model of forest management focused on the development of entrepreneurship in Voronezh region. It is defined, that the main form of forest use in the region is lease of forest lands. The economic mechanism of forest management in these circumstances should be based on the balance of interests of participants of forest relations (the state, society, community, business). At the regional level, the factors restricting development of forestry are high cost of sanitary and health measures and the difficulty of disposing of small merchantable wood and wood fuel after sanitary felling and thinning. It is established that difficulties in the provision of forest land are associated with existing double counting of some lands and forests in Unified state register of real estate. For the analyzed period, the region has developed a stable business trend in the field of forestry to the development of public-private partnerships. It is proved that for the implementation of the principles of sustainable forest management and creation favorable
\end{abstract}


conditions for the development and implementation of economically, environmentally and socially responsible forest development, we need support of business activities, in terms of creating regional infrastructure for support of entrepreneurship in forest sector (sectoral business incubators on the basis of existing research institutes in cooperation with leading forest universities) and ensuring its activities.

Keywords: forestry, protection of forests, tenants of forest areas, forest income

\section{Введение}

Вопросы развития регионального лесного хозяйства актуальны не только в контексте сохранения биоразнообразия флоры и фауны, поддержания гидрологического режима рек и водных бассейнов, качества и устойчивости природной среды, сохранения климата, но и с позиции обеспечения регионального хозяйства ценным сырьем, получения экономического и социального эффектов. Энциклопедический словарь дает следующее определение развития, как необратимое, направленное, закономерное изменение материи и сознания, в результате чего возникает новое качество, состояния объекта его состава или структуры.

Как видно это определение накладывает ограничение на экономический термин развитие, т. е. процесс тесно связан с преобразование количества в качество. Таким образом ведение лесного хозяйства в целях обеспечения его развития должно быть направлено на:

- сохранение и повышение их ресурсноэкологического потенциала;

- увеличение вклада лесов в социальноэкономическое развитие страны, обеспечение экологической безопасности и потребностей экономики в лесных ресурсах, сохранение имеющихся и создание новых качественных рабочих мест;

- удовлетворение общественных потребностей нынешнего и будущих поколений граждан России в ресурсах и услугах леса.

При устойчивом развитии леса являются гарантом предотвращения неблагоприятных климатических изменений, мощнейшим возобновляемым сырьевым источником для лесного комплекса страны, объектом приложения потенциально высокоэффективного труда и получения конкурентоспособной продукции.

Известно, что каждый регион в силу существенных различий в экономическом и социальном развитии и экологическом состоянии территорий должен найти собственные оптимальные решения в области организации многофункционального, непрерывного и неистощительного использования лесных ресурсов, имеющих как рыночную стоимость (через максимизацию рентного дохода), так и предназначенных для удовлетворения общественных потребностей бесплатно [1].

Профессор Н.М. Большаков отмечает, что для достижения и сохранения устойчивого развития необходим мониторинг состояния системы лесного сектора региона, в том числе по некоторому набору критериев и индикаторов, дающих возможность регулярно анализировать параметры ее устойчивости [2].

\section{Результаты и обсуждение}

Лесное хозяйство — важная отрасль экономик регионов, определяющая обеспеченность предприятий и населения в древесине и других продуктах леса. Реформирование Лесного Кодекса РФ открыло новые возможности для перехода лесного хозяйства на путь развития лесного предпринимательства. Воспроизводством и защитой лесов, заготовкой и переработкой древесины занимаются около 60 тысяч крупных, средних и мелких предприятий, расположенных во всех регионах страны [3]. Малолесные регионы включает субъекты с лесистостью менее 20 \% и объединяют Астраханскую область, Белгородскую область, Волгоградскую область, Воронежскую область, Курскую область, Липецкую область, Оренбургскую область, Орловскую область, Ростовскую область, Самарскую область, Саратовскую область, Тамбовскую область, Тульскую область, Ставропольский край, Республику Дагестан, Республику Калмыкия, всего 16 субъектов. Отметим, что леса вышеперечисленных субъектов не обладают значительным сырьевыми ресурсами, являются защитными лесами. Основное направление освоения данной целевой категории лесов предусматривает сохранение их средообразующих, водоохранных, защитных, санитарно- 


\section{Менеджмент. Экономика. Организация}

гигиенических и оздоровительных функций, повышение продуктивности лесов, их воспроизводство и лесоразведение [4].

Для лесов ЦЧР есть и еще одна особенность - это многоцелевое назначение используемых лесных ресурсов. В экономическом плане оно означает, что любое управленческое решение по использованию и воспроизводству лесных ресурсов надо оценивать по совокупности результатов, образующихся от использования древесных, недревесных и социальных полезностей леса [5].

Эти особенности предопределяют специфику управления лесами и характеристики в том числе и экономические предпринимательской среды в малолесных регионах.

В 2006 году принят и в 2008 году полностью вступил в силу действующий Лесной кодекс Российской Федерации, которым установлена принципиально новая система реализации полномочий органов государственной власти и регулирования лесных отношений. Начиная с указанного момента, органами государственной власти проводилась активная работа по дальнейшему реформированию и развитию нормативно-правового регулирования в области лесных отношений с целью обеспечения потребностей граждан в ресурсах и услугах леса, обеспечению их прав на благоприятную окружающую среду.

Характеризуя пройденный этап в целом, можно отметить, что принятые меры привели к улучшению ситуации в лесном комплексе малолесного региона.

Воронежская область является малолесным регионом, с уровнем лесистости $8 \%$. Все леса региона отнесены к категории защитных и как отдельная целевая группа выполняют функции по сохранению благоприятной окружающей среды и условий жизни населения. Экономика регионов малолесной зоны обладает специфическими, противоречивыми особенностями:

- высокий уровень развития лесной инфраструктуры;

- высокая освоенность территорий;
- дефицит лесных ресурсов и полезностей на душу населения;

- высокая плотность населения;

- преобладание лесов, выполняющих средообразующие, водоохранные, защитные, санитарногигиенические, оздоровительные и иные функции;

- преобладание малого бизнеса в осуществления лесохозяйственного производства;

- преобладание искусственного лесовосстановления с высокими затратами.

Учитывая особую экологическую значимость лесов области, вопросам их использования, охраны, защиты и воспроизводства региональным управлением лесного хозяйства уделяется самое пристальное внимание. Задачей первоочередной важности является обеспечение сохранности лесов от пожаров. В области налажена эффективная профилактика и тушение лесных пожаров на основе системы видеонаблюдения «Лесной дозор», объединяющей 46 видеокамер, установленных в наиболее пожароопасных местах произрастания хвойных насаждений (рис. 1).

Мониторинг и ликвидацию пожаров осуществляют 26 пожарно-химических станций. Результат - устойчивая динамика снижения количества и площади лесных пожаров (рис. 2).

Важнейшая задача регионального лесного хозяйства - воспроизводство лесов. В связи с ликвидацией последствий пожаров 2010 года ежегодный объем лесовосстановления увеличился более чем в 2 раза и составляет более 2 тыс. га.

Одним из приоритетных направлений регионального лесного хозяйства является улучшение санитарного состояния лесов, прежде всего в насаждениях, примыкающих к населенным пунктам [6]. В области путем проведения санитарных рубок улучшено санитарное состояние лесов на площади 8,8 тыс. га, в том числе за счет областных средств проведены выборочные санитарные рубки в пригородной черте города Воронежа. Отметим, что дровяная древесина формируемая в значительном объеме при санитарных рубках составляет (около 90\%), не пользуется спросом у населения. 




Рис. 1 - Система организации охраны лесов Воронежской области от пожаров

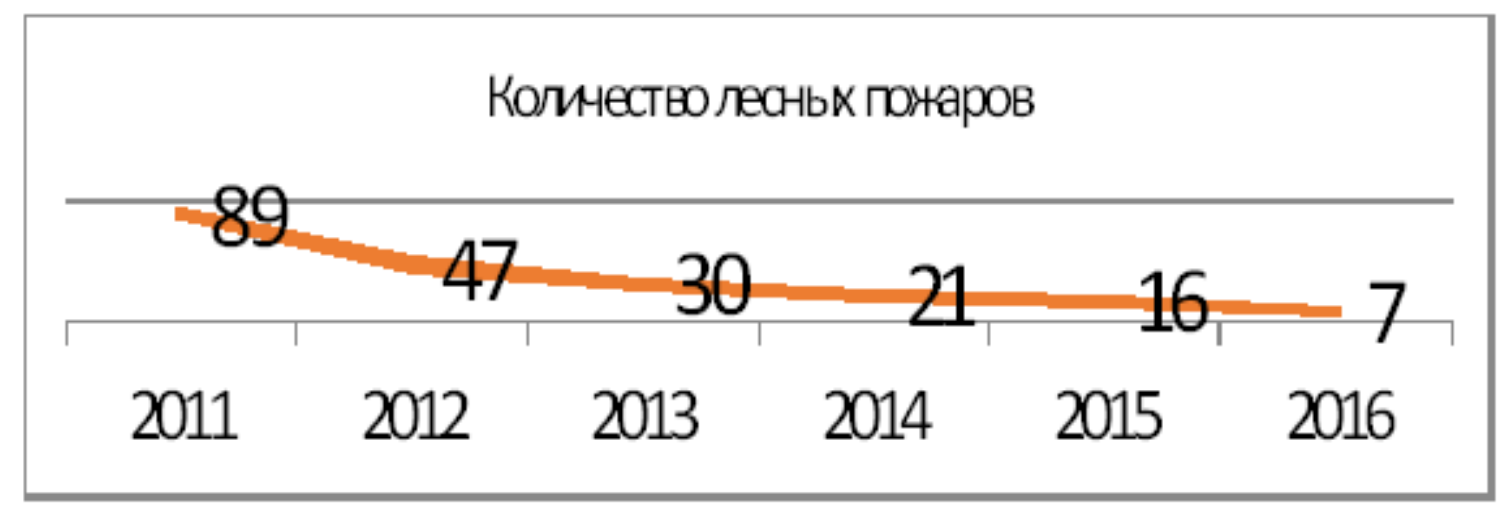

Рис. 2 - Динамика лесных пожаров на территории Воронежской области

В связи с этим доход от заготовки зачастую не покрывает затраты на выполнение санитарнооздоровительных мероприятий, что приводит к снижению их объема. Аналогичная ситуация наблюдается в других регионах России. Нельзя не отметить, что изменения в лесном законодательстве привели к формированию в Воронежской области модели лесопользования ориентированной на развитие предпринимательства.

Начиная с 2008 года участки лесного фонда Воронежской области в границах бывших лесничеств предоставляются в аренду, в том числе и под лесозаготовку. Такая модель в значительной мере соответствует Финской модели, когда лесозаготовительные и лесохозяйственные работы выполняются контракторами на подрядной договорной основе [7].

В отношении условно нового механизма аренды лесных участков отметим, что она является единственной формой возмездного долгосрочного использования лесов с возможностью заключения данного договора широким кругом лиц. Другие основания использования лесов (постоянное (бессрочное) пользование, безвозмездное пользование лесными участками, купля-продажа лесных насаждений) не могут выполнять такую роль, поскольку, во-первых, предполагают пользование лесом довольно узкого круга лиц, а, во-вторых, использование лесных участков такими лицами осуществляется безвозмездно и, как правило, в целях удовлетворения своих потребностей. 
Аренда же лесных участков, как правило, имеет целью осуществление предпринимательской деятельности [8].

В регионе в целях обеспечения рационального использования лесов $36 \%$ земель лесного фонда переданы в аренду, из них 90\% - для заготовки древесины (рис.3).

Ежегодный объем заготовки не превышает $45 \%$ от установленного допустимого годового объема изъятия древесины. Основная причина неиспользования расчетной лесосеки - отсутствие спроса на низкотоварную древесину. Деловая древесина в общем объеме заготовки составляет не более $30 \%$. Серьезная проблема - большие затраты на проведение санитарно-оздоровительных мероприятий и сложности с утилизацией мелкотоварной и дровяной древесины от санрубок и рубок ухода. Существуют трудности в предоставлении лесных участков в пользование в связи с имеющимся двойным учетом некоторых земельных и лесных участков в Едином госреестре недвижимости [9]. Для малолесной зоны вопрос доходности предпринимательской деятельности стоит особенно остро, ввиду низкой ценности из-за большого количества накопленных перестойных насаждений в сочетании с высокой экологической нагрузкой на лесные участки. На сегодняшний день при оценке эффективности управления лесным хозяйством все чаще прибегают к сопоставлению лесных доходов с затратами на лесное хозяйство (рис.4) [10,11].

Следует отметить, что в течение последних лет наблюдается устойчивая положительная динамика поступлений доходов от платы за использование лесов. По сравнению с 2010 годом объем платежей в бюджет России вырос более чем в три раза, в бюджет области - в 20 раз (рис.5).

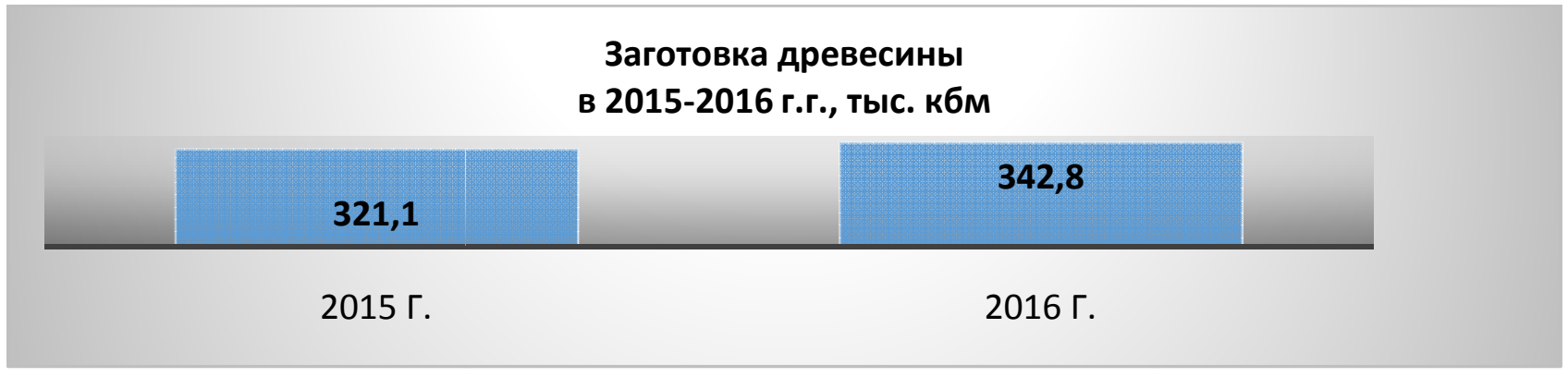

Рис. 3 - Динамика объемов заготовки древесины в лесном фонде Воронежской области

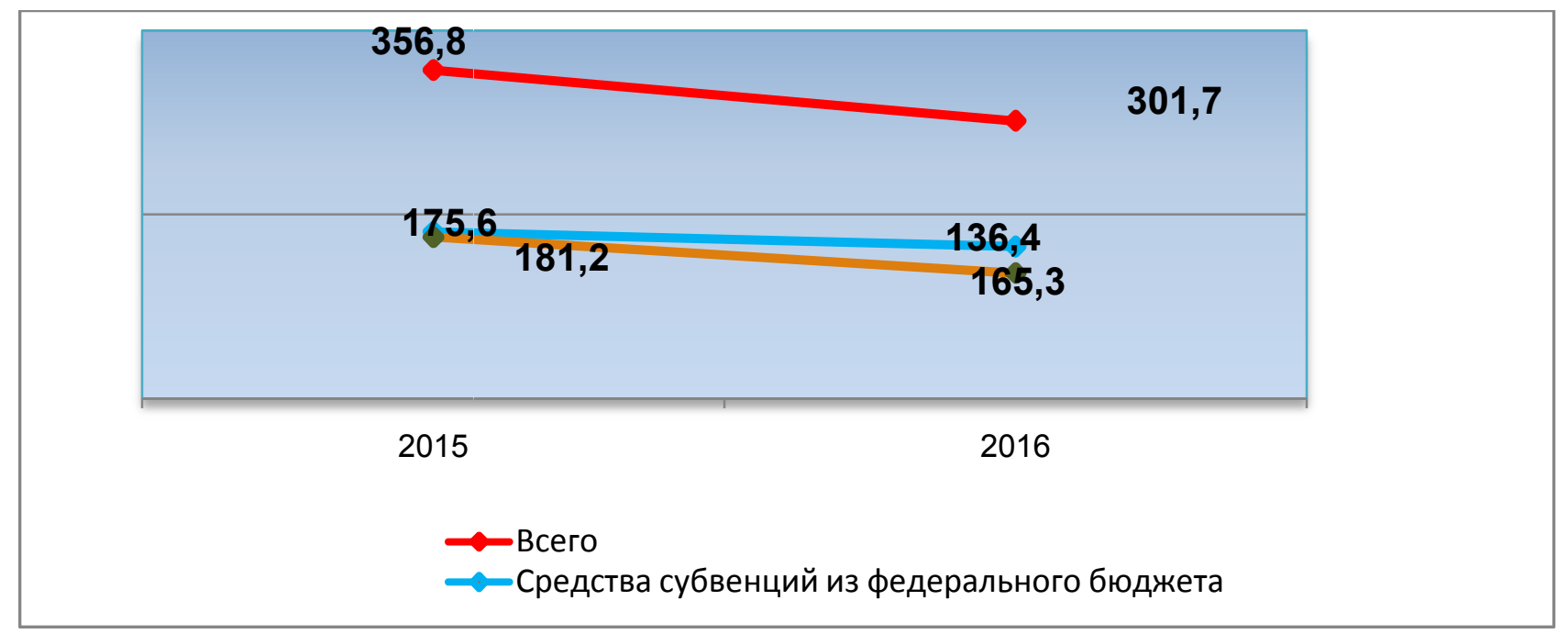

Рис. 4 - Динамика объемов финансирования лесного хозяйства Воронежской области 


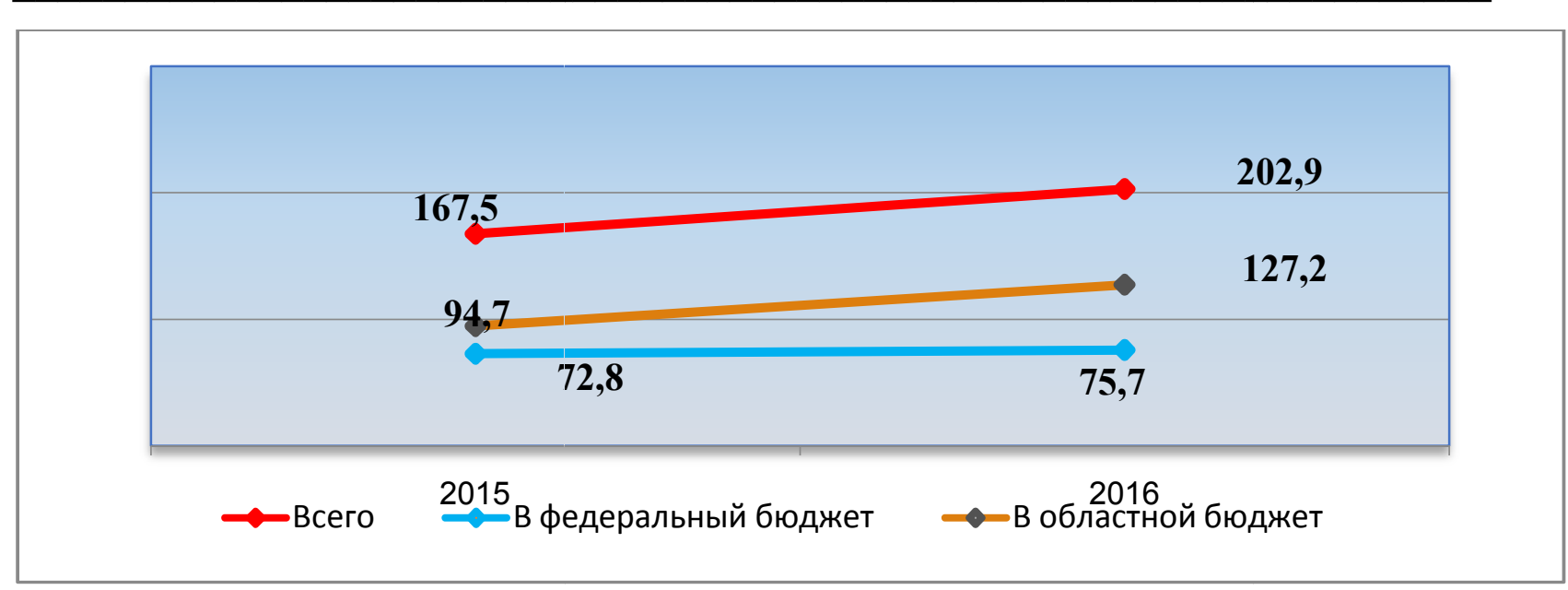

Рисунок 5 - Динамика платежей в бюджеты от использования лесов, млн.р.

Не смотря, на достигнутые положительные результаты, при соотношении доходов и расходов на ведение лесного хозяйства формируется устойчивый дисбаланс. Расходы на управление лесным хозяйством и осуществление лесохозяйственного производства превышают доходы от использования лесов в 1,5-2,0 раза.

В тоже время аналогичная ситуация складывается и в других регионах России. По разным источникам разрыв между затратами на ведение лесного хозяйства и лесным доходом в 2000 г. в целом по стране составлял 6,5 млрд. руб., в 2008 г. он уже составил 13,3 млрд. руб., а в 2011г. - 25,2 млрд. руб.

На наш взгляд такой подход в оценках эффективности лесного хозяйства не совсем корректен для малолесного региона. На практике не существует экономической связи между выделенными субвенциями и платежами за право пользования лесными участками, природа этих показателей абсолютно различна. Для малолесного региона, в который входит ЦЧР, соотношение не в пользу доходов выглядит вполне понятным. Наличие перестойных лесонасаждений, ограничения в формах применяемых рубок, значительная экологическая составляющая не позволяют в полной мере удовлетворить интересы лесозаготовителей, с одной стороны, и высокие затраты на лесовосстановление (преимущественно искусственное) сводят на минимум предпринимательский доход.

Отметим, что в целях увеличения доходной части бюджетов проводятся аукционы по продаже права на заключение договоров купли-продажи лесных насаждений. В 2016 году по итогам 11 аукционов в результате повышения начальной цены в ходе торгов в бюджет области дополнительно перечислили 43,3 млн. рублей. В тоже время фактором ограничивающим эффективность механизма аренды является отсутствие нормативной правовой базы для списания безнадежной к взысканию задолженности по платежам за использование лесов. В настоящее время в соответствии с новациями Бюджетного кодекса России управлением разрабатывается Порядок принятия решения о признании безнадежной к взысканию задолженности по платежам, который позволит привести показатели дебиторской задолженности в соответствие реальным данным и усилить работу по ее сокращению.

Для устранения вышеперечисленных негативных явлений необходима разработка комплекса мероприятий, способствующих совершенствованию механизма взаимодействия арендаторов и органов исполнительной власти в части передачи лесных участков в аренду. Оценивая развитие лесного хозяйства региона отметим, что для определения эффективности осуществления переданных полномочий субъектами Российской Федерации разработаны критерии оценки эффективности деятельности. Эти критерии оценки эффективности деятельности органов государственной власти субъектов РФ по осуществлению переданных полномочий Российской Федерации в области лесных отношений в определены Постановлением правительства РФ № 194 от 6 марта 2012 г. «Об утверждении критериев оценки эффективности деятельности органов государственной власти субъектов российской 


\section{Менеджмент. Экономика. Организация}

федерации по осуществлению переданных полномочий в области лесных отношений» и Приказом Минприроды России от 9 декабря 2014 г. № 545 «Об утверждении Методики оценки эффективности осуществления органами государственной власти субъектов РФ переданных в соответствии со статьей 83 Лесного кодекса РФ полномочий Российской Федерации в области лесных отношений».

Система аналитических показателей представлена абсолютными величинами, характеризующими объем, качество, полноту и (или) своевременность исполнения переданных полномочий и критериями - определяемыми как отношение соответствующих индикаторов оценки эффективности осуществления органами государственной власти субъектов Российской Федерации переданных полномочий Российской Федерации в области лесных отношений, содержащихся в исходных данных для проведения оценки. Сопоставлением значения критерия субъекта Российской Федерации и значений критерия по другим субъектам Российской Федерации оценивается уровень эффективности осуществления переданных полномочий.

По каждому критерию составляется рейтинг уровня эффективности осуществления переданных полномочий субъектами Российской Федерации - место с 1 по 79.

Для проведения оценки используется информация, содержащаяся в:

- отчетах об осуществлении органами государственной власти субъектов Российской Федерации переданных полномочий Российской Федерации в области лесных отношений;

- отчетах о достижении целевых прогнозных показателей;

- ежеквартальных отчетах, о расходовании предоставленных из федерального бюджета субвенций;

- государственном лесном реестре;

- государственной статистической и отраслевой отчетности.

В целях анализа критерии оценки эффективности деятельности органов государственной власти субъектов российской федерации по осуще- ствлению переданных полномочий в области лесных отношений разделенные на семь групп.

- критерии, характеризующие организацию использования лесов, расположенных на землях лесного фонда;

- критерии, характеризующие организацию и обеспечение охраны лесов от лесных пожаров;

- критерии, характеризующие организацию и обеспечение воспроизводства лесов, расположенных на землях лесного фонда;

- критерии, характеризующие организацию и обеспечение защиты лесов, расположенных на землях лесного фонда;

- критерии, характеризующие осуществление на землях лесного фонда федерального государственного лесного надзора (лесной охраны);

- критерии, характеризующие финансовоэкономическую организацию деятельности по осуществлению органами государственной власти субъектов Российской Федерации переданных полномочий Российской Федерации в области лесных отношений;

- критерии, характеризующие сохранение лесов, расположенных на землях лесного фонда.

В период с 2008 по 2016 год (т.е. весь период после введение в действие нового Лесного кодекса) сложилась устойчивая тенденция в предпринимательской сфере лесного хозяйства Воронежской области к развитию государственночастного партнерства. В тоже время, развитие предпринимательства в малолесной зоне характеризуется неравномерностью, причины этого как природно-климатические условия, так и дифференцированная лесистость территории.

Анализируя совокупность критериев в преломлении к задачам настоящего исследования и оценки эффективности развития лесного хозяства региона отметим, что вышеописанная методика для оценки эффективности деятельности органов государственной власти субъектов РФ по осуществлению переданных полномочий Российской Федерации в области лесных отношений содержит ряд индикаторов и критериев характеризующих состояние предпринимательства. Для оценки взаимодействия в области лесных отношений государст- 
венных и предпринимательских структур методическими рекомендациями определено два критерия из группы характеризующей организацию использования лесов, расположенных на землях лесного фонда, и два критерия из группы, характеризующей финансово-экономическую организацию деятельности по осуществлению органами государственной власти субъектов Российской Федерации переданных полномочий Российской Федерации в области лесных отношений.

Выводы. В оценках эффективности управления лесным хозяйством и практики взаимодействия государственных и предпринимательских структур на наш взгляд, следует обращаться не только к количественным показателям таким как, лесной и предпринимательский доходы, но и качественным характеристикам арендуемых участков, выполнения комплекса лесохозяйственных работ, сохранения и приумножения экологических функций лесов. На наш взгляд необходимо введение восьмой группы критериев и соответствующих им индикаторов для характеристики состояния и развития предпринимательской деятельности оценки эффективности взаимодействия властных и предпринимательских структур в системе лесных отношений.
Для малолесного региона, в котором лесопользование ограничивается защитным назначением лесов, их малой площадью в структуре земельных угодий, особой экологической и социальной ценностью необходима поддержка предпринимательской деятельности. В целях повышения эффективности работы по поддержке и развитию предпринимательства осуществляющего лесопользование в малолесной зоне, необходимо ускорить работу по созданию региональных объектов инфраструктуры поддержки малого предпринимательства в сфере лесного хозяйства (отраслевых бизнес-инкубаторов на базе имеющихся НИИ в кооперации с ведущими лесными вузами) и обеспечение её деятельности;

- реализовать комплекс мер по сокращению сроков и этапов прохождения административных процедур субъектами предпринимательской деятельности при согласовании и экспертизе проектов освоения лесных участков;

- разработать механизмы финансовой поддержки предпринимательства в форме субсидирования затрат, связанных с уплатой авансовых лизинговых платежей по договорам лизинга оборудования, лесных машин и механизмов, автотранспортных средств.

\section{Библиографический список}

1. Состояние лесов Европы к 2011 г. // Устойчивое лесопользование. 2011. № 3. С. 2-7.

2. Большаков Н. М., Жиделева В. В. Концептуальные основы устойчивого развития регионального лесного сектора: теория, методология, практика // Известия Коми НЦ УрО РАН. 2012. №4 (12).

3. Зиновьева И.С. Общее и особенное в территориальном распределении и экономическом использовании лесных ресурсов России ./ И.С. Зиновьева// Социально-экономические явления и процессы. - 2013. - №11 (057). - C. 32-36.

4. Burdin N.A., Kachalova N.M., 2010.The forest and forest industry sector of the Russian Federation in the crisis year of 2009, Forest Economic Bulletin, 2010 Contents No. 1 (64).

5. Морковина С.С., Денисова Ю.Г. Детерминанты развития предпринимательства в лесном хозяйстве / Социально-экономические явления и процессы. 2012. № 9 (43). С. 112-116.

6. Morkovina S.S. Innovational mechanisms of biotechnologies support in forest sector for providing economic security of the state / Morkovina S.S., Drapalyuk M.V., Evlakov P.M., Safonova N.A./ Asian Social Science. 2015. T. 11. № 20. C. 41-48.

7. Morkovina S.S. Investigation of Entrepreneurial Structures Forest Management Performance of Forestry System in Sparsely Forest-Poor Region/ Morkovina S.S., E.M. Konovalova, I.V.Sibiriatkina, D. S. Bourtsev/ Asian Social Science Vol.10, No 23, 2014 ISSN 1911-2017 E - ISSN 19112025 Published by Canadian Center of Science and Education 
8. Морковина С.С.Противоречия экономических интересов государства и субъектов малого и среднего предпринимательства, функционирующих в лесном хозяйстве/ С.С.Морковина, И.С.Зиновьева, Бао Шанянь// Лесотехнический журнал. - 2014.- №3(14)c.303-318

9. Korchagin, O.M., Zinovieva, I.S. and Popova, Y.N., (2014), "Descriptive Analysis of Introduction of Innovative Technologies in Forestry”, Asian Social Science, December 2014, Vol. 10, Issue 23, pp. 208-214.

10. Parahina V.N. State support for creation and development of socially-oriented innovative enterprises/ Parahina V.N., Boris O.A., Bezrukova T.L., Shanin I.I. Asian Social Science. 2014. T. 10. № 23. C. 215-222.

11. Epifanova T. Modernization of institutional environment of entrepreneurship in Russia for development of innovation initiative in small business structures / Epifanova T., Romanenko N., Mosienko T., Kupchinskiy A., Skvortsova T. European Research Studies Journal. 2015. T. 18. № 3. C. 137-148.

\section{References}

1. Sostoyanie lesov Evropy k 2011 godu [European forest features by 2011]// Ustoichivoe lesopol'zovanie. 2011. №3, pp. 2-7

2. Bolshakov N.M., Shideleva V.V. Kontseptual'nye osnovy ustoychivogo razvitiya regional'nogo lesnogo sektora: teoriya, metodologiya, praktika [Conceptual foundations of sustainable development of forest sector]// Izvestiya Komi NTs UrO RAN, 2012, №4(12)

3. Zinovyeva I.S. Obshchee i osobennoe v territorial'nom raspredelenii i ekonomicheskom ispol'zovanii lesnykh resursov Rossii ./ I.S. Zinov'yeva// Sotsial'no-ekonomicheskie yavleniya i protsessy. - 2013. - №11 (057). - S. 32-36.

4. Burdin N.A., Kachalova N.M., 2010.The forest and forest industry sector of the Russian Federation in the crisis year of 2009, Forest Economic Bulletin, 2010 Contents No. 1 (64).

5. Morkovina S.S., Denisova Yu.G. Determinanty razvitiya predprinimatel'stva v lesnom khozyaystve / Sotsial'noekonomicheskie yavleniya i protsessy. 2012. № 9 (43). S. 112-116.

6. Morkovina S.S. Innovational mechanisms of biotechnologies support in forest sector for providing economic security of the state / Morkovina S.S., Drapalyuk M.V., Evlakov P.M., Safonova N.A./ Asian Social Science. 2015. T. 11. № 20. C. 41-48.

7. Morkovina S.S. Investigation of Entrepreneurial Structures Forest Management Performance of Forestry System in Sparsely Forest-Poor Region/ Morkovina S.S., E.M. Konovalova, I.V.Sibiriatkina, D. S. Bourtsev/ Asian Social Science Vol.10, No 23, 2014 ISSN 1911-2017 E - ISSN 19112025 Published by Canadian Center of Science and Education

8. Morkovina S.S.Protivorechiya ekonomicheskikh interesov gosudarstva i sub"ektov malogo i srednego predprinimatel'stva, funktsioniruyushchikh v lesnom khozyaystve/ S.S.Morkovina, I.S.Zinov'yeva, Bao Shanyan'// Lesotekhnicheskiy zhurnal. - 2014.- №3(14)s.303-318

9. Korchagin, O.M., Zinovieva, I.S. and Popova, Y.N., (2014), "Descriptive Analysis of Introduction of Innovative Technologies in Forestry", Asian Social Science, December 2014, Vol. 10, Issue 23, pp. 208-214.

10. Parahina V.N. State support for creation and development of socially-oriented innovative enterprises/ Parahina V.N., Boris O.A., Bezrukova T.L., Shanin I.I. Asian Social Science. 2014. T. 10. № 23. C. 215-222.

11. Epifanova T. Modernization of institutional environment of entrepreneurship in Russia for development of innovation initiative in small business structures / Epifanova T., Romanenko N., Mosienko T., Kupchinskiy A., Skvortsova T. European Research Studies Journal. 2015. T. 18. № 3. C. 137-148. 
Сведения об авторах

Скрынникова Мирослава Васильевна - кандидат географических наук, заместитель руководителя Управления лесного хозяйства Воронежской области, г. Воронеж, Российская Федерация; e-mail: uprleshoz@govvrn.ru

Топчеев Андрей Николаевич - аспирант ФГБОУ ВО «Воронежский государственный лесотехнический университет им. Г.Ф. Морозова», доктор экономических наук, профессор, г. Воронеж, Российская Федерация; e-mail: uol.topcheev@rambler.ru

\title{
Information about the authors
}

Skrynnikova Miroslava Vasilievna - Candidate of Geographical Sciences, Deputy Head Department of Forestry of Voronezh region, Voronezh, Russia, e-mail: uprleshoz@govvrn.ru

Topcheev Andrei Nikolaevich - PhD student at FSBEI HE «Voronezh State University of Forestry and Technologies named after G.F. Morozov» Voronezh, Russian Federation; e-mail: uol.topcheev@rambler.ru

DOI: $10.12737 /$ article_59c222199551b3.39294162

УДК 658.26

\section{СТИМУЛЫ И ОГРАНИЧЕНИЯ В РАЗВИТИИ АЛЬТЕРНАТИВНОЙ ЭНЕРГЕТИКИ НА ЛО- КАЛЬНОМ УРОВНЕ:ЗАРУБЕЖНЫЙ И РОССИЙСКИЙ ОПЫТ}

\author{
доктор экономических наук, профессор М.В. Терёшина ${ }^{1}$ \\ кандидат экономических наук, доцент А.Н. Вальвашов 1 \\ 1- ФГБОУ ВО «Кубанский государственный университет», Краснодар, Российская Федерация
}

Цель исследования состояла в компаративном анализе российской и зарубежной практики развития альтернативной энергетики на локальном уровне. Объектом данного исследования является совокупность управленческих воздействий, выступающих детерминантами формирования генерации на основе ВИЭ как составляющей устойчивого развития местных сообществ и «зеленой» экономики. В качестве предмета исследования выступают механизмы, инструменты и практики развития альтернативной энергетики. В качестве основных методов исследования в работе приняты общие теоретические методы исследования: анализ и синтез, а также методы определения показателей, сравнения, группировки и графического изображения. Для оценки «разрывов» между текущим и целевым состоянием «зеленой» энергетики как комплекса управляемых подсистем, авторами предлагается метод GAP-анализа, при этом в качестве основных подсистем выделены доля экологически чистой энергии в общем объеме ее генерации, средняя доля отечественного оборудования и комплектующих в составе электростанций на альтернативной энергии, средний уровень износа оборудования электростанций на альтернативной энергии, среднее время получения разрешения на строительство установок ВИЭ и подключение к центральной энергосети. В статье подробно проанализированы и систематизированы актуальные механизмы стимулирования развития альтернативной энергетики в деятельности муниципалитетов и региональных правительств зарубежных стран. Выделены общие ограничения в развитии альтернативнойэнергогенерации. Проведена дифференциация макрорегионов России по доле «зеленой» энергогенерации в ее совокуп-

\footnotetext{
${ }^{3}$ Исследование проводится при финансовой поддержке РГНФ в рамках проекта «Разработка механизма имплементации концепта «зеленой экономики» в локальные практики местных сообществ» № 16-32-00016
} 